NASA/TM-2003-212593

AIAA-2003-4574

NENA

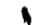

\section{A Comparison of Electric Propulsion Systems for Mars Exploration}

Douglas Fiehler

QSS Group, Inc., Cleveland, Ohio

Steve Oleson

Glenn Research Center, Cleveland, Ohio 
Since its founding, NASA has been dedicated to the advancement of aeronautics and space science. The NASA Scientific and Technical Information (STI) Program Office plays a key part in helping NASA maintain this important role.

The NASA STI Program Office is operated by Langley Research Center, the Lead Center for NASA's scientific and technical information. The NASA STI Program Office provides access to the NASA STI Database, the largest collection of aeronautical and space science STI in the world. The Program Office is also NASA's institutional mechanism for disseminating the results of its research and development activities. These results are published by NASA in the NASA STI Report Series, which includes the following report types:

- TECHNICAL PUBLICATION. Reports of completed research or a major significant phase of research that present the results of NASA programs and include extensive data or theoretical analysis. Includes compilations of significant scientific and technical data and information deemed to be of continuing reference value. NASA's counterpart of peerreviewed formal professional papers but has less stringent limitations on manuscript length and extent of graphic presentations.

- TECHNICAL MEMORANDUM. Scientific and technical findings that are preliminary or of specialized interest, e.g., quick release reports, working papers, and bibliographies that contain minimal annotation. Does not contain extensive analysis.

- CONTRACTOR REPORT. Scientific and technical findings by NASA-sponsored contractors and grantees.
- CONFERENCE PUBLICATION. Collected papers from scientific and technical conferences, symposia, seminars, or other meetings sponsored or cosponsored by NASA.

- SPECIAL PUBLICATION. Scientific, technical, or historical information from NASA programs, projects, and missions, often concerned with subjects having substantial public interest.

- TECHNICAL TRANSLATION. Englishlanguage translations of foreign scientific and technical material pertinent to NASA's mission.

Specialized services that complement the STI Program Office's diverse offerings include creating custom thesauri, building customized databases, organizing and publishing research results ... even providing videos.

For more information about the NASA STI Program Office, see the following:

- Access the NASA STI Program Home Page at http://www.sti.nasa.gov

- E-mail your question via the Internet to help@sti.nasa.gov

- Fax your question to the NASA Access Help Desk at 301-621-0134

- Telephone the NASA Access Help Desk at 301-621-0390

- Write to: NASA Access Help Desk NASA Center for AeroSpace Information 7121 Standard Drive Hanover, MD 21076 
(nasis

\section{A Comparison of Electric Propulsion Systems for Mars Exploration}

Douglas Fiehler

QSS Group, Inc., Cleveland, Ohio

Steve Oleson

Glenn Research Center, Cleveland, Ohio

Prepared for the

39th Joint Propulsion Conference and Exhibit

cosponsored by the AIAA, ASME, SAE, and ASEE

Huntsville, Alabama, July 20-23, 2003

National Aeronautics and

Space Administration

Glenn Research Center 
Available from

NASA Center for Aerospace Information 7121 Standard Drive Hanover, MD 21076
National Technical Information Service 5285 Port Royal Road Springfield, VA 22100

Available electronically at http://gltrs.grc.nasa.gov 


\title{
A COMPARISON OF ELECTRIC PROPULSION SYSTEMS FOR MARS EXPLORATION
}

\author{
Douglas Fiehler* \\ QSS Group, Inc. \\ Cleveland, Ohio 44135 \\ Steve Oleson ${ }^{\dagger}$ \\ National Aeronautics and Space Administration \\ Glenn Research Center \\ Cleveland, Ohio 44135
}

\begin{abstract}
Earth-Mars trajectories for multiple solar-powered spacecraft configurations were generated using Hall and ion propulsion systems utilizing the Direct Trajectory Optimization Method. Payload and power trades versus trip time were examined. Performance was compared for purely interplanetary flight and interplanetary flight with estimated spiral in to Mars orbit. Evaluating current ion and Hall thruster technologies, similar payload masses were delivered by each at equivalent trip times, but with the Hall thruster operating at a power level 10 kilowatts, on average, less than the ion thruster. The power difference for equivalent payload delivered should result in a significant cost savings.
\end{abstract}

\section{INTRODUCTION}

NASA has identified Mars as an important interplanetary destination due to its proximity and interest to the space science community. Approximately every two years, the synodic period of the Earth-Mars system, the distance between the bodies reaches a minimum. Previous missions have capitalized on this dating back to the 1960 s with the Mariner flyby missions and continued with the Viking landers in the 1970s and the Mars Pathfinder lander/rover in the 1990s. Currently, the Mars Global Surveyor and 2001 Mars Odyssey are orbiting the Red Planet. And just recently, the Mars Express and MERA/B missions were launched. Planning continues for the next synodic period opportunity in 2005 with the Mars Reconnaissance Orbiter ${ }^{1}$.

Solar electric propulsion (SEP), first flightdemonstrated in the $1960 \mathrm{~s}^{23}$, uses power provided by solar arrays to accelerate a working fluid that propels a spacecraft. Many studies have been performed to show the applicability and performance of SEP systems for interplanetary missions. The study of SEP main-belt asteroid $^{4.5}$ and comet $^{4}$ missions has shown benefit with both ion and Hall thruster propulsion. Other missions to planets and their moons have also been studied and shown feasible with SEP, such as Pluto flyby ${ }^{5}$ and Europa orbiter ${ }^{4}$ missions. SEP Mars missions have also been studied. SEP sample return missions to Mars' moon Phobos ${ }^{5}$ as well as orbiter and sample-return missions directly to Mars ${ }^{4.6}$ have been studied and show the benefit from the application of SEP.

Each of these interplanetary missions analyzed required 20-100 kilowatts of on-board power at launch, which is substantial compared to the 2.5 kilowatts required by the recent Deep Space 1 (DS1) spacecraft? However, DS1 was the first time NASA implemented an interplanetary spacecraft incorporating substantial on-board power specifically for primary propulsion applications. This paradigm shift represents a willingness of NASA to accept the additional costs and complexity of SEP systems to achieve substantial performance benefits relative to traditional chemically propelled spacecraft. In light of this paradigm shift, SEP missions to Mars using currently available technologies were evaluated. For these analyses ion and Hall thruster propulsion technologies, which have both been used operationally, were considered. These two propulsion technologies, which have been evaluated through development projects that are ongoing $^{8,9}$, have complimentary performance. State-ofthe-art (SOA) ion thrusters can provide specific impulses $\left(I_{S P}\right)$ ranging from 2500 to 4000 seconds with efficiencies between $50 \%$ and $70 \%$. SOA Hall thrusters can provide 1500 to 3500 seconds of $I_{S P}$ with efficiencies between $45 \%$ and $65 \%$.

The goal of this study was to assess SOA ion and Hall system performance benefits for a Mars orbiter mission. Performance comparisons were made to assess each system's strengths. The missions analyzed

* Member AIAA

${ }^{\dagger}$ Senior Member AIAA 
all have similar baselines with different arrival schemes. The baseline mission launched on a Delta IV $(5,4)$ launch vehicle to Earth-escape. The SEP interplanetary portion of the mission had a burn-coastburn profile ("burn" refers to the electric propulsion system producing thrust). Arrival at Mars was analyzed with three different arrival schemes. First, the interplanetary trajectory was examined alone to simulate capture into a high Mars orbit, to study the Mars-Phobos-Deimos system for example, or as a communications relay satellite. This trajectory was similar to an aerobrake or aerocapture trajectory, but aerobraked or aerocaptured missions were beyond the scope of this analysis and the tools used. An SEP spiral to an altitude appropriate for the study of Mars' satellite, Deimos, and to low Mars orbit for planetary studies were also estimated for total trajectory performance comparisons. The impacts of using each different propulsion technology on mission capability are discussed.

\section{SPACECRAFT SYSTEM AND MISSION DEFINITION}

Prior to performing the mission analysis, the spacecraft and mission were defined. For these analyses, the spacecraft model was kept generic to assess results based on thruster performance and not spacecraft and system mass considerations. The spacecraft mass model accounted for mass changes resulting from the varying power level, both from the power system (array) mass and the changing number of thrusters required on the spacecraft. It also adjusted the mass of the payload structure and tankage based on the payload mass and propellant mass.

\section{Spacecraft Definition}

The spacecraft system model used was an updated version of the JPL Team $X$ spacecraft from the baseline next generation ion design reference mission analyses ${ }^{4}$. The spacecraft was defined as having six components: fixed SEP stage, payload, payload structure, propellant, propellant tank, and power system. The fixed SEP stage accounted for thrusters, power processing units, feed systems, and any associated structure. The payload and propellant were determined by the optimized trajectory. Payload mass was determined by subtracting all other spacecraft components from the launch mass. Propellant was calculated by multiplying mass flow rate by thruster operation time. A fraction of payload and propellant mass defined the payload structure and propellant tank masses, respectively. Finally, the power system mass was calculated using a specific mass, that is, unit mass of power system per unit power required. Table 1 details the parameters used to define the spacecraft. The total mass of the spacecraft was defined as follows

$$
\begin{aligned}
m_{\text {wet }}= & m_{S E P}+m_{P L}+K_{s t} m_{P L}+ \\
& m_{\text {prop }}+K_{t} m_{\text {prop }}+\alpha P_{0}
\end{aligned}
$$

where $m_{w e t}$ is the spacecraft wet mass, $m_{S E P}$ is the fixed SEP stage mass, $m_{P L}$ is the payload mass, $K_{S T}$ is the payload structure fraction, $m_{\text {prop }}$ is the propellant mass, $K_{t}$ is the tankage fraction, $\alpha$ is the power system specific mass, and $P_{0}$ is the initial spacecraft power.

Table 1: Spacecraft Defining Parameters

\begin{tabular}{|l|c|}
\hline SEP Stage Mass $\left(m_{\text {SEP }}\right)$ & $577 \mathrm{~kg}$ \\
\hline Payload Structure Fraction $\left(K_{s t}\right)$ & 0.085 \\
\hline Tankage Fraction $\left(K_{t}\right)$ & 0.156 \\
\hline Power System Specific Mass $(\alpha)$ & $9.2 \mathrm{~kg} / \mathrm{kW}$ \\
\hline
\end{tabular}

\section{Propulsion System}

\section{Ion Propulsion System}

The ion propulsion system utilized a 1.5 to 6 kilowatt thruster that operated at specific impulses $\left(I_{S P}\right)$ between approximately 3000 and 4000 seconds and efficiencies between approximately $55 \%$ and $70 \%$. The performance of the thruster was tied to available power through a throttle table (see Figures 1 and 2). For the following analyses, only the curve defining the high $I_{S P}$ versus power was used.

The power available also determined the number of thrusters operated at any given time. Because the thruster was power-constrained, thrusters were turned off as the power dropped with distance to the Sun squared and vice-versa as the available power increased. In instances where it was possible to run a higher number of thrusters at lower $I_{S P}$ and efficiency or a lower number of thrusters at higher $I_{S P}$ and efficiency,

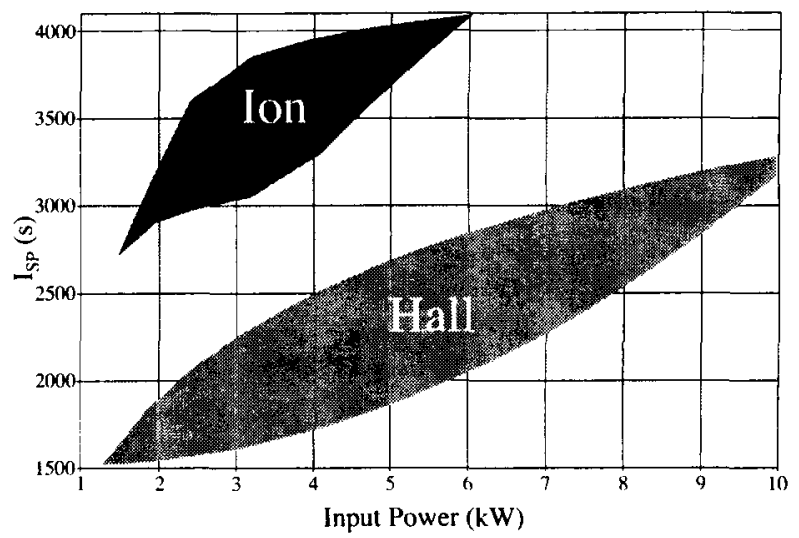

Figure 1: Specific Impulse vs. Power Throttle Table 


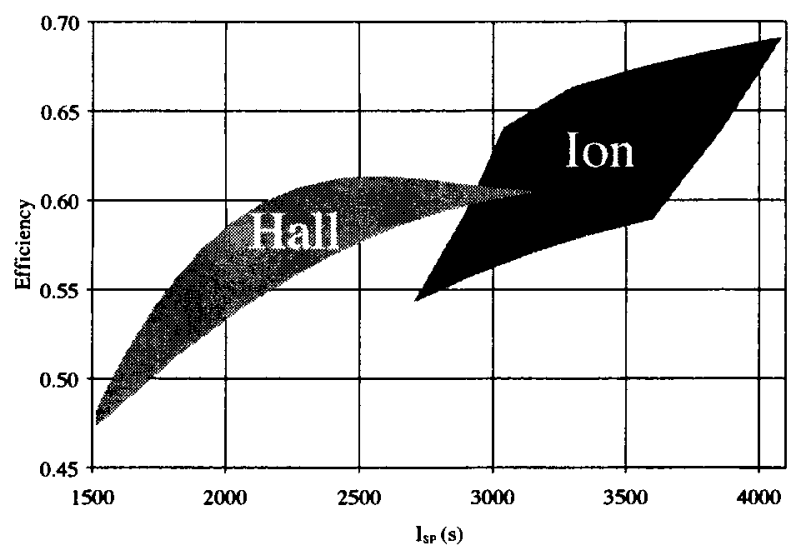

Figure 2: Efficiency vs. Specific Impulse

fewer thrusters were operated because of enhanced performance. A minimum of two thrusters was used during periods of thrusting to maintain roll control.

\section{Hall Propulsion System}

The Hall thruster system was modeled similar to the ion thruster. The throttle table ranged from $1.3 \mathrm{~kW}$ to $10 \mathrm{~kW}$ in power, approximately 1500 seconds to 3400 seconds in $I_{S P}$, and approximately $45 \%$ to $60 \%$ in efficiency (see Figures 1 and 2). Once again, only the high $I_{S P}$ curve was used. Because the SOA power levels differ for these technologies, ion and Hall thrusters operating in the same power range would not have represented current capabilities. Thus, the Hall thruster's wider power range with higher maximum power compared to the ion thruster, required fewer thrusters, which reduced spacecraft mass and complexity.

\section{Mission and Trajectory Optimization Method}

\section{Direct Trajectory Optimization Method}

Trajectory design and optimization was completed using the Direct Trajectory Optimization Method (DTOM) code. As the name suggests, the DTOM is a direct method for obtaining optimal, low-thrust, interplanetary trajectories ${ }^{10}$. The DTOM numerically integrates the equations of motion using modified equinoctial orbital elements to accommodate circular orbits $(e=0)^{11}$. The parameterized continuous-time control, thrust and coast lengths, launch date scaling factor, and Earth-escape parameters define the generic design space. More specialized problems can be defined with planetary gravity assists, loiter periods at the target body (used for sample-return missions), optimization of power level and specific impulse (either single value or parameterized continuous-time profile), and specialized thruster system models.

Thruster performance can be modeled in one of several ways depending on mission requirements. For single-point operation, a constant power, $I_{S P}$, and efficiency can be specified. The second option relates specific impulse and efficiency $(\eta)$ independent of power through the use of two performance constants, $b b$ and $d d$, using the following relationship

$$
\eta=\frac{b b I_{S P}{ }^{2}}{d d^{2}+I_{S P}{ }^{2}}
$$

The third method, and the technique used for these studies, is a throttle table relating thruster power processing unit (PPU) input power to specific impulse and efficiency (see Figures 1 and 2). Because a range of specific impulse exists at discrete power levels, one must choose between operating at the upper or lower boundary of $I_{S P}$, or at a point between determined by the optimizer. Once these three parameters are determined, the thrust magnitude, used in the equations of motion, was calculated using the following equation

$$
T=\frac{2 \eta P}{g I_{S P}}
$$

where $T$ is the thrust produced,

$P$ is the PPU input power, and $g$ is the acceleration of gravity.

\section{Mission Definition and Analysis Method}

The mission used for these analyses was a direct Earth-Mars transfer launching in early 2014 with a thrust-coast-thrust profile. The spacecraft was launched to escape using a Delta IV $(5,4)$ launch vehicle. A duty cycle of $90 \%$ was assumed to allow for navigation updates during thrusting. Parameters optimized by the DTOM were the parameterized continuous-time steering profile, thrusting and coasting period lengths, launch energy $\left(C_{3}\right)$, departure angles from low Earth

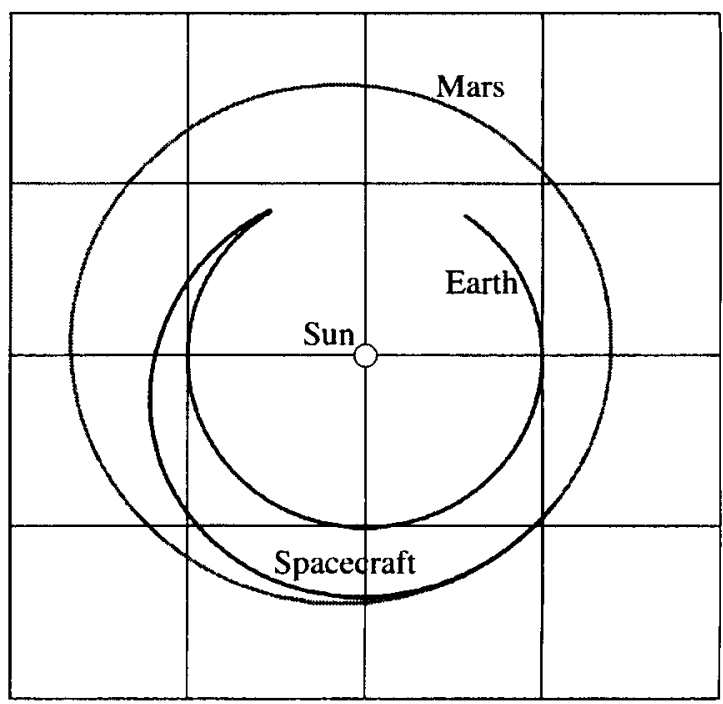

Figure 3: Sample Earth-Mars Trajectory 
orbit, and PPU input power at Earth departure. A sample trajectory can be seen in Figure 3 .

Fixed trip time trajectories were utilized to complete the analysis. The spacecraft payload was maximized for trip times ranging from 250 to 600 days. Sets of optimal trajectories for each propulsion option were generated and used to draw the conclusions found herein.

These analyses were used for comparison of the interplanetary travel. However, estimated spirals to a near-Deimos altitude of $23,520 \mathrm{~km}$ and $400 \mathrm{~km}$ altitude were included for additional performance comparisons. This estimation was completed using the method described by Battin in Reference 12. In this analytical formulation, the tangential thrust acceleration was assumed constant, but considering low-thrust spacecraft the decreasing mass must be accounted for in thrust acceleration calculations. Therefore, the average tangential thrust acceleration over the spiral was used in the calculation, and the spiral time $\left(t_{s}\right)$ was approximated by

$$
t_{s}=\frac{\sqrt{\mu / r_{0}}}{\bar{a}_{T_{t}}}\left[1-(20)^{1 / 4}\left(\frac{r_{0}{ }^{2} \bar{a}_{T_{t}}}{\mu}\right)^{1 / 2}\right]
$$

where $\mu$ is the gravitational parameter of the attracting body,

$r_{0}$ is the initial circular orbit radius for escape or final circular orbit radius for capture, and

$\bar{a}_{T_{t}}$ is the average tangential thrust acceleration over the spiral trajectory.

The final mass after spiral was then calculated by multiplying the mass flow rate of the thruster by the spiral time. This final mass was then used to recalculate the final and average thrust accelerations and this process was iterated until convergence.

\section{ELECTRIC PROPULSION SYSTEM PERFORMANCE}

Analysis was completed through the generation of maximum payload trajectories over a range of trip times. Payload and initial power curves for each of the three arrival cases are presented in Figures 4 through 6 . The ion and Hall thrusters consistently delivered roughly equivalent payload mass to Mars over the majority of the range of trip times. The only advantage was that the Hall thruster delivered more payload mass at the shortest trip times and the ion thruster delivered more mass at the longest trip times. These payload

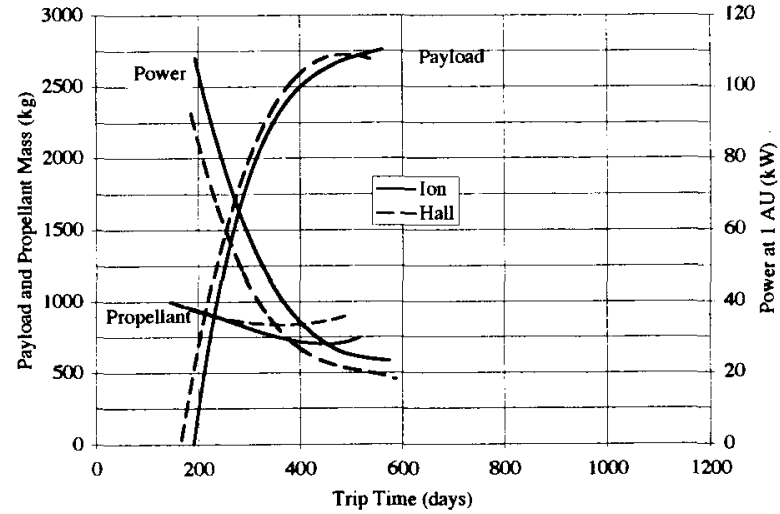

Figure 4: Payload, Power at 1 AU, and Propellant vs. Trip Time, Interplanetary Trajectory Only

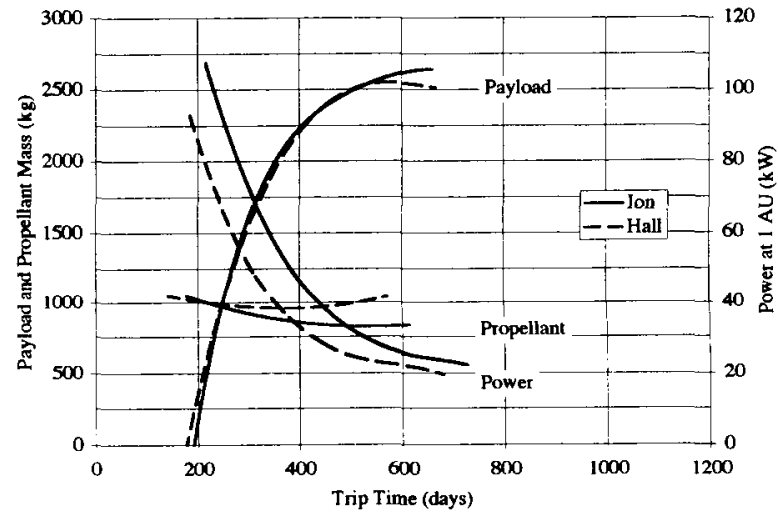

Figure 5: Payload, Power at $1 \mathrm{AU}$, and Propellant vs. Trip Time, Interplanetary Trajectory with Mars Spiral to Deimos

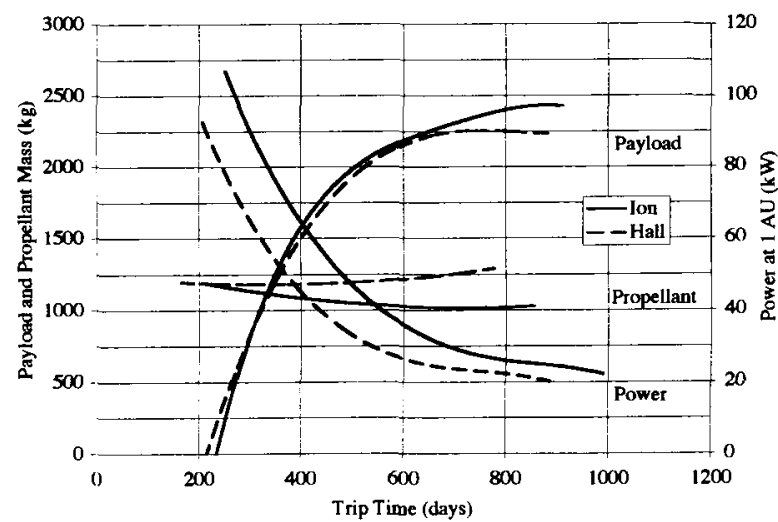

Figure 6: Payload, Power at $1 \mathrm{AU}$, and Propellant vs. Trip Time, Interplanetary Trajectory with Mars Spiral to $400 \mathrm{~km}$ Altitude

advantages were exaggerated as the spiral distance increased.

The relationship of propellant to $I_{S P}$ was also evident. Because mass flow rate was considered inversely proportional to specific impulse squared, according to the following equation, 


$$
\dot{m}=\frac{T}{g I_{S P}}=\frac{2 \eta P}{\left(g I_{S P}\right)^{2}}
$$

and the Hall thruster operated at a lower $I_{S P}$ than the ion, it used more propellant (see Figures 4-6). This relationship held except for very short trip times where the power level required by the ion thruster at $1 \mathrm{AU}$ (Astronomical Unit, the average distance from the Earth to the Sun) was high.

The factor that separated the performance of the ion and Hall thrusters dramatically was the power level required from the solar arrays at $1 \mathrm{AU}$ (see Figures 46). For the strictly interplanetary trip times, the Hall thruster power level at $1 \mathrm{AU}$ was an average of $10 \mathrm{~kW}$ less than the ion thruster for the three arrival schemes. The reduced size of the solar array required for the Hall thruster spacecraft could potentially save $\$ 1$ million per kilowatt.

The final relationship evident from these performance plots was the effect of the spiral on the performance of these systems. As expected, as the spiral distance increased, the total trip time also increased. Also, as the required power level decreased with increased trip times the spiral trip time increased. This relationship had the effect of stretching the curves toward longer trip times with increasing spiral distances.

Each of these propulsion systems operated in the high power range of their throttle tables (see Figure 7). A minimal amount of throttling was required by these propulsion systems to successfully complete this mission. The propulsion systems began by processing the highest power allowable by their respective throttle tables. As the power dropped with increasing distance to the Sun, thrusters were switched off and the high power end of the throttle table was utilized again.

Figure 7 illustrated the difference between the thrusters' operating points. This difference

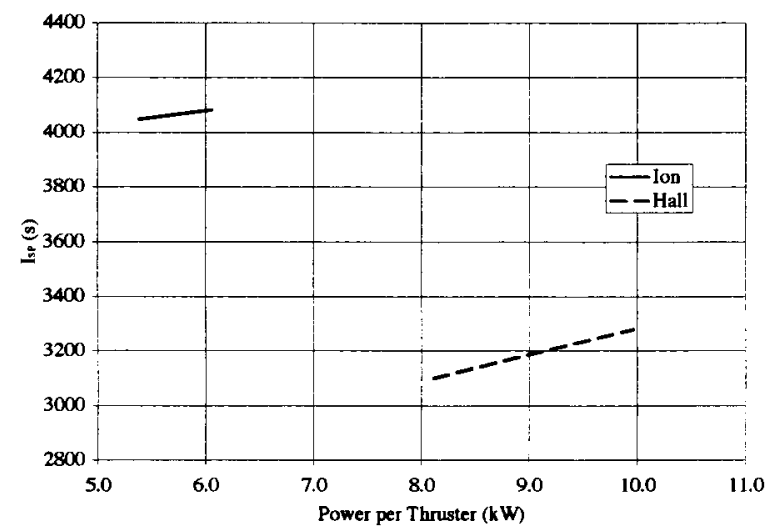

Figure 7: Specific Impulses Utilized by each Propulsion System for the 200-day Interplanetary Trip Time Case demonstrated one reason why the Hall thruster outperformed the ion, especially at the short trip times. The Hall system's lower $I_{S p}$, which produced more thrust and reduced the required power and power system mass, and its ability to process more power per thruster than the ion system, which reduced the system mass, combined to allow the Hall system to deliver equivalent payload mass as the ion system but at lower power levels.

Examination of the launch energy $\left(\mathrm{C}_{3}\right)$ provided insight into the relative performance of these systems. Figure 8 showed the relationship of $C_{3}$ to the interplanetary trip time. At short trip times higher launch energies were used, at the cost of launch mass, to propel the spacecraft to higher velocities. The spacecraft implementing the Hall thruster system used higher $\mathrm{C}_{3}$ at the shorter trip times to reduce the $v$ (velocity change induced by the SEP system) required by the propulsion system. Because payload mass delivered was approximately equal over the range of trip times, the trade then became one between propellant mass and power system mass. The lower power level required by the Hall thruster system reduced the power system mass, which allowed an increase in propellant mass. Conversely, the ion thruster system's higher required power level increased the power system mass. The difference between these masses on the spacecraft was the fact that the power system was brought, as a whole, to the destination while the propellant mass decreased over the length of the trip. That is, a constant fraction of the total power was required to propel the power system to the destination while a decreasing fraction of the total power was required to propel the propellant load to the destination. Because the Hall thruster spacecraft had lower power levels, the ability to process more propellant, and delivered equivalent payload mass as the ion spacecraft, the Hall thruster's $I_{S P}$ was more optimal for this mission than the ion thruster's $I_{S P}$.

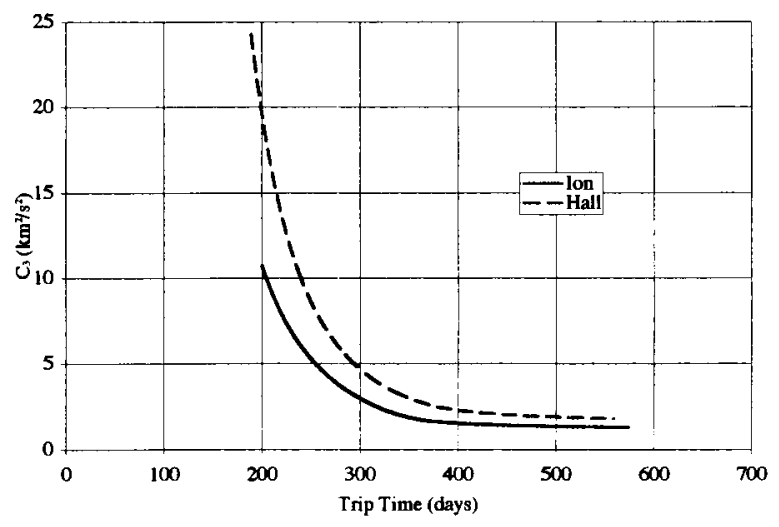

Figure 8: Launch Energies Required over the Range of Interplanetary Trip Times 


\section{IMPACTS AND ASSESSMENTS}

Hall and ion thruster systems are appropriate propulsion systems for Mars exploration. Each of these systems have heritage through flight demonstrations and have technology development programs in progress. Hall thrusters typically do not have the lifetime of ion thrusters, but the trip times demonstrated for this Mars mission are of same order of magnitude of current Hall thruster lifetimes. Because of the Hall thruster's lower optimal power, it may be more appropriate than the ion for these missions, as long as the increased propellant loading for the Hall thruster is not prohibitive.

The development of higher power thrusters also is beneficial. Fewer thrusters operating at higher power reduces the required system mass such that performance is improved over a system with more thrusters operating at lower power levels. This can be seen in a general sense with this study. The Hall thruster's delivered payload mass is buoyed by the fact that fewer thrusters were required to operate at the higher power levels (shorter trip times) because it operated at up to $10 \mathrm{~kW}$ per thruster as opposed to the ion which operated at up to $6 \mathrm{~kW}$ per thruster. This power-to-mass relationship also supports the development of higher power thrusters, such as HiPEP (ion) and HIVHAC (Hall) funded through NASA Research Announcements.

The minimum trip time demonstrated by this study was approximately 200 days. However, at these short trip times, minimal payload was delivered to Mars. Chemically propelled spacecraft can complete the journey from Earth to Mars in slightly less than 200 days, when Earth and Mars are at their closest approach, and deliver a useful amount of payload mass. Therefore, a comparison which needs to be made, but was not included in this study, is the performance of a SEP spacecraft versus a comparable chemically propelled spacecraft.

These missions required significantly higher power levels for propulsion than have been demonstrated on DS1. As solar power systems for spacecraft are developed to higher power levels, the Hall thruster spacecraft Mars missions will be enabled before the ion thruster. In fact, for a required payload mass to be delivered to Mars, the Hall thruster will always require lower power levels than the ion thruster in this spacecraft configuration. Therefore, the Hall thruster can be considered a nearer-term technology for this Mars mission.

\section{CONCLUSIONS}

Maximum payload Earth-Mars trajectories were generated to assess the performance of SOA ion and Hall thrusters. The ion and Hall thrusters delivered approximately equivalent payload masses over a range of trip times. However, the Hall thruster required less power than the ion thruster. This power savings is substantial in terms of the cost of spacecraft systems. The lower powered Hall system used fewer thrusters, which is also a benefit due to the reduced complexity of the propulsion system, and also make it a nearer-term technology as solar power systems evolve to higher powers. Minimum transfer times for this mission were approximately 200 days and comparisons must be made to similarly configured chemically propelled spacecraft. The relative performance of these systems showed that the $I_{S P}$ of the Hall thruster system was more optimal for this mission than that of the ion propulsion system. Inclusion of the spirals around Mars in the numerical optimization and allowing optimization of the $I_{S P}$ profile within the bounds of the throttle table would improve upon these analyses. While the Hall thruster system may have outperformed the ion thruster for this Mars orbiter mission, by its nature, the ion thruster will outperform the Hall for other missions for which it is more suited. Both ion and Hall thruster systems have a place in the repertoire of interplanetary propulsion systems.

\section{REFERENCES}

[1] NASA's Mars Exploration Program Website, http://mars.jpl.nasa.gov/

[2] Martinez-Sanchez, M., Pollard, J. E., "Spacecraft Electric Propulsion-An Overview," Journal of Propulsion and Power, Vol. 14, No. 5, SeptemberOctober 1998, pp. 688-699

[3] Sovey, J. S., Rawlin, V. K., Patterson, M. J., "Ion Propulsion Development Projects in the U.S.: Space Electric Rocket Test I to Deep Space I," Journal of Propulsion and Power, Vol. 17, No. 3, May-June 2001, pp. 517-526

[4] Brophy, J. R., Noca, M., "Electric Propulsion for Solar System Exploration," Journal of Propulsion and Power, Vol. 14, No. 5, September-October 1998, pp. $700-707$

[5] Williams, S. N., Coverstone-Carroll, V., "Benefits of Solar Electric Propulsion of the Next Generation of Planetary Exploration Missions," The Journal of the Astronautical Sciences, Vol. 45, No. 2, AprilJune 1997, pp. 143-159 
[6] Williams, S. N., Coverstone-Carrol, V., "Mars Missions Using Solar Electric Propulsion," Journal of Spacecraft and Rockets, Vol. 37, No. 1, JanuaryFebruary 2000, pp. 71-77

[7] Rayman, M. D., Williams, S. N., "Design of the First Interplanetary Solar Electric Propulsion Mission," Journal of Spacecraft and Rockets, Vol. 39, No. 4, July-August 2002, pp. 589-595

[8] Oleson, S., Gefert, L., Benson, S., Patterson, M., Noca, M., Sims, J., "Mission Advantages of NEXT: NASA's Evolutionary Xenon Thruster," AIAA Paper 2002-3969, July 2002

[9] Hofer, R. R., Jankovsky, R. S., "The Influence of Current Density and Magnetic Field Topography in Optimizing the Performance, Divergence, and Plasma Oscillations of High Specific Impulse Hall Thrusters," IEPC Paper 2003-142, March 2003
[10] Kluever, C. A., "Optimal Low-Thrust Interplanetary Trajectories by Direct Method Techniques," Journal of the Astronautical Sciences, Vol. 45. No. 3, July-September 1997, pp. 247-262

[11] Betts, J. T., "Optimal Interplanetary Orbit Transfers by Direct Transcription," Journal of the Astronautical Sciences, Vol. 42, No. 3, 1994, pp. 247-268

[12] Battin, R. H., Astronautical Guidance, McGrawHill Book Company, New York, 1964 


\begin{tabular}{|c|c|c|c|}
\hline \multicolumn{3}{|c|}{ REPORT DOCUMENTATION PAGE } & $\begin{array}{l}\text { Form Approved } \\
\text { OMB No. 0704-0188 }\end{array}$ \\
\hline \multicolumn{4}{|c|}{ 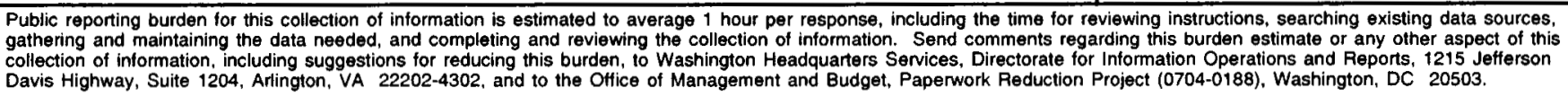 } \\
\hline 1. AGENCY USE ONLY (Leave blank) & $\begin{array}{l}\text { 2. REPORT DATE } \\
\text { September } 2003\end{array}$ & 3. $\mathrm{R}$ & $\begin{array}{l}\text { D DATES COVERED } \\
\text { echnical Memorandum }\end{array}$ \\
\hline \multicolumn{3}{|c|}{$\begin{array}{l}\text { 4. TITLE AND SUBTITLE } \\
\text { A Comparison of Electric Propulsion Systems for Mars Exploration }\end{array}$} & \multirow{2}{*}{$\begin{array}{l}\text { 5. FUNDING NUMBERS } \\
\text { WBS-22-982-10-03 }\end{array}$} \\
\hline \multicolumn{3}{|c|}{$\begin{array}{l}\text { 6. AUTHOR(S) } \\
\text { Douglas Fiehler and Steve Oleson }\end{array}$} & \\
\hline \multicolumn{3}{|c|}{$\begin{array}{l}\text { 7. PERFORMING ORGANIZATION NAME(S) AND ADDRESS(ES) } \\
\text { National Aeronautics and Space Administration } \\
\text { John H. Glenn Research Center at Lewis Field } \\
\text { Cleveland, Ohio } 44135-3191\end{array}$} & $\begin{array}{l}\text { 8. PERFORMING ORGANIZATION } \\
\text { REPORT NUMBER } \\
\text { E-14150 }\end{array}$ \\
\hline \multicolumn{3}{|c|}{$\begin{array}{l}\text { 9. SPONSORING/MONITORING AGENCY NAME(S) AND ADDRESS(ES) } \\
\text { National Aeronautics and Space Administration } \\
\text { Washington, DC 20546-0001 }\end{array}$} & $\begin{array}{l}\text { 10. SPONSORING/MONITORING } \\
\text { AGENCY REPORT NUMBER } \\
\text { NASA TM-2003-212593 } \\
\text { AIAA-2003-4574 }\end{array}$ \\
\hline
\end{tabular}

\section{SUPPLEMENTARY NOTES}

Prepared for the 39th Joint Propulsion Conference and Exhibit cosponsored by the AIAA, ASME, SAE, and ASEE, Huntsville, Alabama, July 20-23, 2003. Douglas Fiehler, QSS Group, Inc., Cleveland, Ohio 44135, and Steve Oleson, NASA Glenn Research Center. Responsible person, Douglas Fiehler, organization code 5430, 216-433-2584.

12a. DISTRIBUTION/AVAILABILITY STATEMENT

Unclassified-Unlimited

Subject Category: 13
Distribution: Nonstandard

Available electronically at http://gltrs.grc.nasa.gov

This publication is available from the NASA Center for AeroSpace Information, 301-621-0390.

13. ABSTRACT (Maximum 200 words)

Earth-Mars trajectories for multiple solar-powered spacecraft configurations were generated using Hall and ion propulsion systems utilizing the Direct Trajectory Optimization Method. Payload and power trades versus trip time were examined. Performance was compared for purely interplanetary flight and interplanetary flight with estimated spiral in to Mars orbit. Evaluating current ion and Hall thruster technologies, similar payload masses were delivered by each at equivalent trip times, but with the Hall thruster operating at a power level 10 kilowatts, on average, less than the ion thruster. The power difference for equivalent payload delivered should result in a significant cost savings.

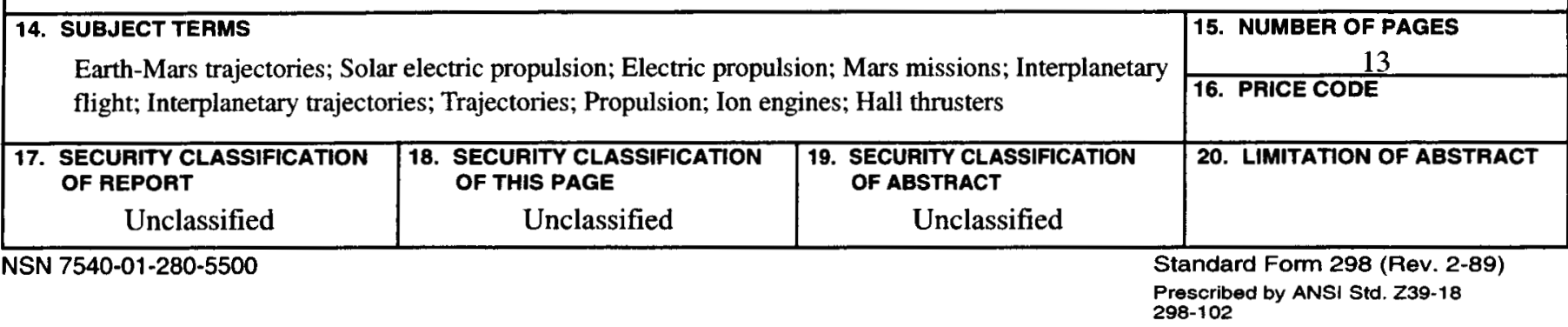

